\title{
Challenges in Performing Nail-Fold Capillaroscopy during COVID-19
}

\author{
Deepak Jakhar ${ }^{\mathrm{a}}$ Chander Grover ${ }^{\mathrm{b}}$ \\ ${ }^{a}$ Department of Dermatology, North Delhi Municipal Corporation Medical College \& Hindu Rao Hospital, New Delhi, \\ India; ${ }^{\text {b}}$ Department of Dermatology \& STD, University College of Medical Sciences \& GTB Hospital, New Delhi, India
}

Dear Editor,

Nail-fold capillaroscopy (NFC) is a non-invasive, in vivo diagnostic tool for the assessment of microvasculature of the proximal nail fold [1]. The utility of NFC in diagnosing, monitoring, and prognosticating connective tissue diseases is well established. The procedure requires a digital capillaroscope/videodermatoscope, which comes in direct contact with digits of the patient [2]. With uncertainty surrounding the disease transmission and the novel severe acute respiratory syndrome coronavirus (SARS-CoV-2) pandemic scenario, performing NFC has become challenging.

Studies have indicated the presence of SARS-CoV-2 on the surface of daily use items, persisting on surfaces for up to 5-7 days [3-6]. Thus, any instrument used in daily clinical practice can potentially act as a fomite and a source of transmission [5, 6]. COVID-19-positive symptomatic patients and asymptomatic carriers have the potential to transmit the virus to the capillaroscope while doing NFC, either through direct contact with the fingers of the patients or through aerosol transmission. Thus, a simple procedure like NFC can potentially result in transmission of COVID-19. This brings up a very pertinent question: what considerations should be kept in mind while doing NFC during COVID-19 era?

$\begin{aligned} & \text { karger@karger.com } \\ & \text { www.karger.com/sad }\end{aligned}$
Karger

Hands are a potential source for transmitting any infection (including COVID-19) as they frequently come in contact with other human beings and non-living objects and surfaces [7, 8]. Henceforth, the importance of hand hygiene has been advocated by the World Health Organization (WHO) [9]. Owing to their unique anatomy and proximal and distal nail folds, nails most easily pick up infective particles and also are most difficult to clean/sterilize as compared to other parts of the hand. Cleaning the nails is thus an essential step in hand washing. Nail unit makes the transmission to and from the capillaroscope very plausible. At the same time, the need for performing NFC in patients with connective tissue diseases may be high as many of them would be on immunosuppressive drugs for their disease, and important decisions regarding altering treatment options may need to be taken for them. For these decisions, NFC may play a contributory role. One may argue that a procedure like NFC can be easily deferred during COVID-19. Though elective NFC can be avoided at this time, given the simplicity of this procedure and the sophistication of information it provides, NFC is a valuable option in situations that require treatment modification and follow-up of a patient. NFC can give important information about the activity of disease, tendency to develop digital tip ulceration, and inter-

Chander Grover

Department of Dermatology and STD

University College of Medical Sciences and GTB Hospital

Dilshad Garden, Dehli 110095 (India)

chandergroverkubba@ rediffmail.com 
nal organ involvement $[10,11]$. This may assume additional importance in view of acro-ischemia being increasingly reported to be associated with COVID-19 [12]. A study of nail-fold capillaries might be helpful in evaluating patients predisposed to develop this cutaneous complication. Thus, instead of discarding it all together, it is better to perform it (wherever necessary) with extra precautions.

For NFC, patient's hand needs to be kept at the level of the heart on a table [2]. The surface of the table should be cleaned with $0.5 \%$ sodium hypochlorite or $70 \%$ isopropyl alcohol, and patient's hand should be washed with soap and lukewarm water for at least $20 \mathrm{~s}$ (cold water can cause vasoconstriction and hot water can cause vasodilation). The capillaroscope should be cleaned with 70\% isopropyl alcohol $[5,6]$. In addition, both the patient and the clinician should wear a protective face mask (N95 respirator, if recommended) and practice distancing (distance $>1 \mathrm{~m}$ or $6 \mathrm{ft}$ ) or face shields, as much as possible. During the procedure, the clinician should wear disposable gloves, and alcohol-containing immersion fluid should be used, taking care that the capillaroscope has minimal contact with the digits. Disposable caps or polyethylene tube can be connected to the capillaroscope for preventing crossinfection [13]. These can be discarded after single use.
Since the fourth and fifth fingers usually provide adequate information, it is better to avoid NFC in all 5 fingers and limit the duration of the procedure [2].

It is still uncertain how long COVID-19 pandemic will last. However, with slight modifications in our clinical practice, we can make patient care safer for us and for our patients. With resumption of dermatology services, these precautionary measures can be incorporated in the routine NFC examination of patients, especially those with acro-ischemic digital changes.

\section{Conflict of Interest Statement}

The authors have no conflicts of interest to declare.

\section{Funding Sources}

The authors did not receive any funding.

\section{Author Contributions}

Both the authors have contributed equally.

\section{References}

1 Cutolo M, Sulli A, Secchi ME, Olivieri M, Pizzorni C. The contribution of capillaroscopy to the differential diagnosis of connective autoimmune diseases. Best Pract Res Clin Rheumatol. 2007;21(6):1093-108.

2 Jakhar D, Grover C, Singal A. Nailfold capillaroscopy with USB dermatoscope: a crosssectional study in healthy adults. Indian J Dermatol Venereol Leprol. 2020 Jan-Feb; 86(1):33-8

3 Kampf G, Todt D, Pfaender S, Steinmann E. Persistence of coronaviruses on inanimate surfaces and its inactivation with biocidal agents. J Hosp Infect. 2020;104(3):246-51

4 Van Doremalen N, Bushmaker T, Morris DH, Holbrook MG, Gamble A, Williamson BN, et al. Aerosol and surface stability of SARSCoV-2 as compared with SARS-CoV-1. N Engl J Med. 2020 Apr 16;382(16):1564-67.

5 Jakhar D, Kaur I, Kaul S. Art of performing dermoscopy during the times of coronavirus disease (COVID-19): Simple change in approach can save the day! [published online ahead of print, 2020 Mar 29]. J Eur Acad Dermatol Venereol. 2020;34(6):e242-44.
6 Jakhar D, Bhat YJ, Chatterjee M, Keshavmurthy V, Ankad BS, Jha AK, et al. Dermoscopy practice during COVID-19 pandemic: recommendations by SIG dermoscopy (IADVL Academy). Indian Dermatol Online J. 2020 May-Jun;11(3):343-4.

7 WHO Guidelines on Hand Hygiene in Health Care: First Global Patient Safety Challenge Clean Care Is Safer Care. Geneva: World Health Organization; 2009. 7, transmission of pathogens by hands. Available from: https:// www.ncbi.nlm.nih.gov/books/NBK144014/

8 Beamer PI, Plotkin KR, Gerba CP, Sifuentes LY, Koenig DW, Reynolds KA. Modeling of human viruses on hands and risk of infection in an office workplace using micro-activity data. J Occup Environ Hyg. 2015;12(4):26675.

9 World Health Organization. Critical preparedness, readiness and response actions for COVID-19-7 March 2020. Available from: https: //www.who.int/publications-detail/ critical-preparedness-readiness-and-response-actions-for-covid-19.
10 Hofstee HM, Vonk Noordegraaf A, Voskuyl AE, Dijkmans BA, Postmus PE, Smulders YM, et al. Nailfold capillary density is associated with the presence and severity of pulmonary arterial hypertension in systemic sclerosis. Ann Rheum Dis. 2009;68(2):1915.

11 Sebastiani M, Manfredi A, Colaci M, D'amico R, Malagoli V, Giuggioli D, et al. Capillaroscopic skin ulcer risk index: a new prognostic tool for digital skin ulcer development in systemic sclerosis patients. Arthritis Rheum. 2009;61(5):688-94

12 Calvão J, Relvas M, Pinho A, Brinca A, Cardoso JC. Acro-ischaemia and COVID-19 infection: clinical and histopathological features. J Eur Acad Dermatol Venereol. 2020 Jun.

13 Jakhar D, Grover C, Kaur I. Polyethylene tube as an attachment to universal serial bus (USB) dermatoscope for preventing cross-infection [published online ahead of print, 2020 Mar 31]. Indian J Dermatol Venereol Leprol. 2020; 86(4):459-60. 